\title{
Climate information for humanitarian agencies: some basic principles
}

\author{
Erin Coughlan de Perez ${ }^{1}$ and Simon J Mason ${ }^{2^{*}}$
}

\begin{abstract}
Since 2005, the International Federation of Red Cross and Red Crescent Societies and the Red Cross Red Crescent Climate Centre have had an ongoing partnership with the International Research Institute for Climate and Society (IRI) to connect end-users with providers of climate information. This partnership has enabled and encouraged the uptake of climate information in the humanitarian sector. From the perspective of the climate service provider, attempts to address problems of salience, credibility and legitimacy have been made by adopting the following set of principles: prioritize immediate user needs; provide only information that is relevant to the user context; provide decision support; right-scale rather than down-scale; and maintain ownership and partnership in design. Examples are presented of how these principles have been applied, highlighting not only the need to improve forecasts and their presentation, but also to address obstacles to the practical use of climate information.
\end{abstract}

Keywords: Humanitarian; Seasonal forecasts; Climate; Service; Partnership; Early warning

\section{Introduction}

More than two thirds of the mortality and economic losses caused by natural hazards are weather or climate related (United Nations International Strategy for Disaster Reduction 2009), but, when adequately informed, humanitarian actors can take action to prevent such hazards from becoming disasters (Braman et al. 2010; Hellmuth et al. 2011; Intergovernmental Panel on Climate Change 2012). To promote this provision of necessary weather and climate information for early action, the World Meteorological Organization (WMO) now houses a Global Framework for Climate Services (GFCS) in which governments, the climate community, and end-users partner to improve climate services worldwide (Hewitt et al. 2012). One of the four priority areas of the GFCS is on disaster risk reduction, asserting that application of climate services in this field can reduce hydrometeorological disaster risk.

To ensure the usefulness of climate information in disaster risk reduction, collaboration between end-users and information providers is essential. Interaction between these two groups is seen as one of the key challenges in the use of climate services (Braman et al. 2012), and user-

\footnotetext{
* Correspondence: simon@iri.columbia.edu

${ }^{2}$ International Research Institute for Climate and Society, The Earth Institute of Columbia University, PO Box 1000, Palisades, NY 10965, USA

Full list of author information is available at the end of the article
}

provider partnerships are one of the eight principles to guide implementation of the GFCS (Hewitt et al. 2012). This paper provides key principles for institutions on the methods for establishing and sustaining such collaboration, particularly for providers of climate information who would wish to work more closely with end-users.

Since 2005, the International Federation of Red Cross and Red Crescent Societies (IFRC) and the Red Cross Red Crescent Climate Centre have partnered with the International Research Institute for Climate and Society (IRI) to connect end-users with providers of climate information. This partnership has enabled and encouraged the uptake of climate information in the humanitarian sector, rapidly evolving to account for changing needs and new information. Innovative decision support tools and methods for collaboration have resulted from the close working relationship, and have been applied to address disaster risk in a variety of settings.

This paper analyses some of the outcomes of this partnership, characterizing the collaborative methods that were used to achieve success in the application of climate services in the Red Cross Red Crescent Movement. We identify principles that guide the collaboration and provide examples of the innovations in climate services that have resulted. Following these principles, organizations within and outside of the humanitarian sector can

\section{Springer}


replicate much of the methodology that has contributed to a successful partnership and the uptake of climate services in the Red Cross Red Crescent Movement.

\section{Organisational context}

The Red Cross Red Crescent Movement is the world's largest humanitarian organization, and has taken initiative worldwide to assess the role of climate on humanitarian operations. Housing several climate focal persons and a climate reference institution, the Movement has been actively involved in discussions around climate services from a user perspective. Representatives from the IFRC as well as national Red Cross and Red Crescent Societies regularly participate in the Conference of Parties to the UNFCCC, advocating on behalf of the most vulnerable who will be affected by decisions on mitigation and adaptation. Representatives often attend Regional Climate Outlook Forums (Ogallo et al. 2008) and participate in national climate working groups (Pascal et al. 2012).

Over the six years of the IRI-Red Cross partnership, climate information has successfully been used to take preventative action for disaster. This has ranged from prepositioning disaster relief stocks in West Africa based on a 2008 seasonal forecast (Braman et al. 2010; Braman et al. 2012), to a drought emergency appeal by the Kenya Red Cross in January 2011 that cited the La Niña as a reason to prepare for imminent drought (Kenya Red Cross. Drought (Early Warning Early Action) 2011). During the same La Niña event, seasonal forecasts were distributed widely to National Red Cross Societies in the small island states of the Pacific (McNaught et al. 2013). These areas tend to experience periods of drought associated with La Niña, and the populations are at risk of waterborne disease due to lack of clean water. Based on this information, the Red Cross societies of Kiribati and Tuvalu campaigned nationally to create awareness about typhoid, appropriate hygiene practices, and methods for water conservation.

However, the probabilistic nature of seasonal forecasts ensures that there will be instances in which the most likely category of rainfall does not materialize. The year following the 2010-2011 drought in East Africa, a weak La Niña re-emerged, but the rainfall over East Africa was above-normal, rather than the most likely category of below-normal. While most action taken to prepare for the impacts of seasonal forecasts is useful in the long-term (i.e.: investments in water storage infrastructure), such events can undermine trust of climate information in those who do not fully recognize the probabilistic nature of forecasts.

Examining these events and other climate-related initiatives within the Red Cross Red Crescent Movement, this paper focusses on the partnership with climate forecast providers that exists behind the stories of successful action. The paper describes some of the principles that have contributed to making the partnership successful in ultimately improving services to the populations who are most vulnerable to climate variability and change.

\section{Report: Principles of engagement}

Climate information is under-utilized in many sectors for a variety of reasons: the salience, credibility, and legitimacy of such information are primary hindrances to its more effective use (Johnston et al. 2004; Klopper et al. 2006; Meinke et al. 2009; Hansen et al. 2011). In building a partnership between climate information users and providers, each and every one of these hindrances needs to be addressed before information will translate into action. The following principles characterize how the issues of salience, credibility and legitimacy have been addressed within the context of the IFRC-IRI partnership to promote the uptake of climate services within the Red Cross Red Crescent Movement.

\section{Prioritize immediate user needs}

As they research and develop climate information, climate scientists can easily foresee the potential value for such information in humanitarian work and other sectors. However, within humanitarian organizations, the same vision does not necessarily exist, even if climate information would in fact be useful if it were applied (Dilling and Lemos 2010). The usefulness of information and the demand for information are not identical; therefore scientists must assess both components when collaborating with an end-user organization.

Demands for information derive from standard operating practices that are well established within humanitarian organizations; these practices govern the flow of information and the acceptable criteria for decision-making. If climate products do not provide knowledge that is actionable within the current framework, they are not perceived as useful. While these standard practices can and do change over time to accommodate new sources of information and new methods for making decisions, there is inertia built into the system that prevents the immediate uptake of information as soon as it is presented.

In the case of climate information, probabilistic forecasts of three-month seasonal rainfall totals are not demanded by traditional humanitarian operating systems; instead, decision-makers are interested in the likelihood of exceptionally heavy rainfall in the coming days, as a proxy for flood risk that can precipitate early action. Given this situation, the IRI-IFRC partnership began by addressing existing demand within the humanitarian movement for assistance in interpreting global weather forecasts, as an entry point to the use of more long-term climate forecasts in the future.

Although disaster managers were already accessing forecasts of total precipitation, they were struggling to 
identify precisely where locally heavy rainfall was forecast. After a series of discussions, the partnership identified a way to present the information in an understandable format, and developed an online maproom resource that featured 6-day "extreme rainfall" forecasts as the landing page. The maps were then incorporated into disaster monitoring tools used by the IFRC on a regular basis. Subsequently, it was possible to expand the maproom to include climate forecasts and information on ENSO events, but the successful distribution of the seasonal forecast tool within the IFRC occurred because it addressed existing demand for information. Over time, the concept of "seamless" forecasting, integrating short-term, seasonal, and long-term projections has helped users envision the usefulness of seasonal information based on their existing use of short-term information.

Provide only information that is relevant to the user context When working with end-users, the information provided by resource institutions needs to be directly relevant to the decision at hand; extraneous information can be confusing and can ultimately hinder action. The extent to which information is presented to directly address users' questions, rather than epistemic meteorological questions, is a critical factor determining uptake. In the context of the IFRC maproom, a map of the amount of rainfall that is forecast to fall in a given location is not necessarily relevant to a humanitarian worker; instead, action is taken based on predictions of anomalously high rainfall relative to what is usually expected in that location. The problem with a forecast of rainfall amounts in the eyes of a humanitarian worker is two-fold: it requires expert information about the background climatology to identify where the forecast shows locally heavy rainfall, and the actual amount of rainfall that is required for locally heavy rainfall does not matter to the disaster manager. The maproom landing page was therefore designed to highlight locations in blue that are forecasted to receive rainfall in the top percentiles of historical amounts for that location.

Iterative reformatting of the maproom has been required to help ensure that the information is both understandable to the humanitarian actor and scientifically consistent to the provider (Johnston et al. 2004; Usman et al. 2006). Originally, accompanying text for the maproom was presented in the provider's language: the map legend showed percentile thresholds depicted on a colour scale, and the map title provided information about the dataset used for these forecasts (called "ESRL GEFS SixDay Precipitation Forecast"). Focusing on the decisions that would be made based on this map, IRI eventually reformatted the page to remove extraneous information. The title is now posted in the form of a question directly related to the utility of the map ("Where is exceptionally heavy rainfall expected?"), and further information about the dataset is moved to a tab called "Dataset documentation." The legend is also given a qualitative format, describing different colours on the map as "Heavy Rainfall," "Very Heavy Rainfall," and "Extremely Heavy Rainfall," with further information available should the user require it. The text next to the map no longer describes rainfall percentiles, but provides suggestions to the user about action that can be taken to reduce possible disaster effects, such as, "Contact your local/regional meteorological department and monitor their forecasts for the next six days," and "Review your contingency plans and update as necessary".

\section{Provide decision support}

Climate information is only useful to a humanitarian organization if it can trigger action that ultimately increases the efficiency or effectiveness of disaster mitigation or response; information as a stand-alone product transferred from producer to user is not necessarily valuable (Vogel and O'Brien 2006; Webster 2013). Unfortunately, probabilistic forecasts of three-month seasonal rainfall totals do not easily fit within the decision system of humanitarian organizations for at least two reasons: the time-scale and the level of uncertainty in the forecast. These organizations are accustomed to responding to disasters in situations where a crisis exists or is imminent, and the chances of "acting in vain" are minimal. Most also have an ongoing portfolio of disaster risk reduction interventions to reduce long-term disaster risk; the chance of a disaster happening at some point in the long-term future after a project has been completed is unquestionable, thereby justifying these interventions without fear of "acting in vain".

Because the current system does not provide tools for acting based on seasonal probabilistic information, individuals within the Red Cross Red Crescent Movement fear personal culpability for making unconventional decisions based on new, probabilistic information (Suarez and Tall 2010). Whether an action was "in vain" is a subjective judgement applied to a specific situation, such as an evacuation followed by no hurricane, but acting based on a high probability of hurricane landfall is justified even though landfall is not certain. Therefore, decision support systems are needed to aid disaster managers in assessing probabilistic risk and help them convert climate information into appropriate actions that recognize both the risk of acting in vain and the potential to save lives and livelihoods with successful action.

In the Pacific, the Red Cross translates the regional Island Climate Update into a humanitarian-specific decision support tool with the help of the IRI. This decision support tool lists the rainfall forecast for each island nation, possible humanitarian impacts, and suggested actions 
by the Red Cross societies to prevent these impacts. The update is disseminated throughout the region to inform decision-making in light of climate uncertainties, and references newly-developed resources such as drought action checklists.

The IRI developed a "Ready-Set-Go" framework to illustrate the parsing of decisions across timescales, triggered by climate information. At the first stage, seasonal forecasts trigger organizations to "get ready" by updating contingency plans, training volunteers, and sensitizing at-risk communities in the general region of the forecast. These actions tend to be low-regret actions, minimizing the negative consequences of acting in vain. For example, training additional volunteers does divert resources from other activities, but these volunteers will be useful in any future emergency, whether or not the forecasted season holds a disaster situation.

The second phase, "get set" focuses on mid-range forecasts at higher resolution and skill, which would trigger humanitarian agencies to warn specific regions about impending rainfall anomalies and carry out local preparation activities. The third phase, "go!" is triggered by short-range forecasts at high resolution with the highest accuracy, and the humanitarian agency would deploy an assessment team, activate volunteers, and take locallyappropriate action such as evacuation (Hellmuth et al. 2011). Thus, for a particular hazard, such as flooding, action can be taken to reduce risk in the near-term and also on longer timescales; humanitarian organizations do not distinguish between climate and weather information as do climate and weather scientists.

The Ready-Set-Go concept can also be extended to timescales beyond that of seasonal forecasts. While the scale and application of action that is appropriate will differ across timescales, best practices for dealing with disaster risks can be consistent across lead-times. For example, in Kenya, latrines help prevent diarrheal disease associated with heavy rainfall; therefore training community members on how to construct a flood-proof latrine would be relevant based on climate change projections, providing materials to support construction of latrines would be relevant based on a seasonal forecast, and alerting people to reinforce and maintain their latrines would become relevant based on a short-term forecast of heavy rainfall.

In a Rockefeller-funded project on Health Risk Management in a Changing Climate, the Red Cross societies of Kenya, Tanzania, Vietnam, and Indonesia developed action plans for reducing disease risk in the near-term and in the long-term. Given projections of impacts of climate change showing that changing rainfall is likely to affect disease incidence, the Red Cross societies developed educational materials to promote continued vigilance in monitoring and preventing diarrheal disease in East Africa and dengue fever in Southeast Asia. Each location created a contingency plan for actions that can be taken on a seasonal basis, increasing preventative action before seasonal peaks of disease, and scaling up activity when a seasonal forecast predicts an increased chance of an above-normal rainfall season. In the short-term, contingency plans made use of daily and weekly rainfall forecasts to alert vulnerable community members in flood-prone areas and sound the alarm for increased action to prevent disease.

\section{Right-scale rather than down-scale}

Climate information is often seen to be irrelevant for decision-making if locally-specific predictions are not available, which is a common misconception. While downscaling is an active area of research, seasonal forecasts are currently coarse resolution and focus on national or district scales. However, research has indicated that increased probability of above-normal seasonal rainfall totals in standard forecasts is correlated with increases in the chances of heavy rainfall events within the same region. If large enough areas are considered, and forecasters do not attempt to predict the precise location of a disaster event within this area, there is evidence for the predictability of extreme rainfall events on a seasonal scale (Hellmuth et al. 2011). Such region-wide changes in disaster risk can be used to make a number of initial decisions, without need for highly uncertain, highly localized information.

In this way, the concept of "right-scaling", or using information available at large geographical scales to inform decision-making on those same geographical scales, can yield societal benefits. Because seasonal forecasts can be useful to indicate changes in the risk of heavy rainfall over a large area; IRI has collaborated with the Red Cross Red Crescent Climate Centre to gather information on the relationship between seasonal rainfall forecasts and disaster events, focusing on decisions that could be made at the national or regional scale to prepare for disaster. These actions do not require forecasts to provide information on specific communities, and can apply to entire regions. Existing decision support tools are being continually reworked to develop a thresholds analysis for color-coding the forecast according to the most appropriate decisions for each threshold of risk.

A successful implementation of this concept is the preventative action taken in West Africa in 2008 to preposition stocks in anticipation of a season that was forecasted to likely have above-normal total rainfall. In this case, supplies were imported from warehouses in other continents, and stored in the West Africa regional offices to be ready for deployment. While the warning did not allow the humanitarian workers to anticipate the actual flooding location, the IFRC monitored short-term forecasts for further information, and the prepositioned stocks ultimately increased the efficiency of the humanitarian response. 
Supplies reached beneficiaries in days, compared to the expected response rate on the order of weeks (Braman et al. 2010; Braman et al. 2012).

\section{Maintain ownership and partnership in design}

Throughout all of these examples, the close collaboration between the IRI and the Red Cross Red Crescent Movement is predicated on trust and confidence in the quality and reliability of the information being provided. Jointly designing both information and decision support tools fosters ownership of the tools and encourages their use. To achieve this, the Red Cross Red Crescent Movement has a focal person who is closely affiliated with IRI and given access to the institute's resources and facilities. This "liaison" is responsible for bridging the divide between the producers and end-users of the forecast information, and ensures that the views of the scientists and the humanitarian agencies are represented in the development of forecast information and tools.

The IRI also offers a "helpdesk" specifically for the Red Cross Red Crescent Movement, to ensure open lines of communication and easy access to cutting-edge climate information. This email-based helpdesk guarantees a onebusiness-day turnaround in response to questions about climate and weather by making use of the academic resources and staff at the IRI to source simple, relevant answers. Additional information can be provided as a follow-up, in which case the IRI staff will often seek assistance from experts on/within the region in question. Humanitarian workers have posed questions about historical climate behaviour and possible long-term threats in their location, the availability of reliable information on sea level rise projections, whether to attribute extreme events to climate variability or climate change, and how to navigate between differing forecast signals for the same region. The ability to respond to these questions with simple answers has cultivated humanitarian interest in the effect of climate on their work, and increased willingness to adjust existing standard protocols and make decisions based on climate information.

\section{Conclusions}

The opportunities and interest in using climate information within the Red Cross Red Crescent movement are continually growing, and much of this progress can be attributed to application of the principles of addressing issues with the salience, credibility and legitimacy of the information. Since 2006, more than 60 national Red Cross and Red Crescent Societies have participated in a "Preparedness for Climate Change" program to investigate and plan for climate risks in their countries. Decision support has been based on a realistic assessment of the user context, demand-driven yet reflecting current forecasting capabilities.
Moving forward, continual user-driven analysis is needed to transform seasonal forecast information into knowledge that can be used to trigger decision-making. Further research into seasonal forecasts for extreme events is necessary to improve the range of decisions that can be informed based on climate information. While rainfall intensity reflects a good deal of atmospheric "noise", there is evidence that frequency of rainfall above a certain threshold might show considerable forecasting skill at the seasonal level, perhaps even greater than the existing skill of total rainfall forecasts (Moron et al. 2007; Robertson et al. 2009; Verbist et al. 2010). Recent research also indicates potential skill in forecasting subseasonal scenarios (Moron et al. 2013). Such advances in our ability to predict patterns of extreme events at the seasonal scale could enable more robust humanitarian decisions with greater potential for avoiding disaster worldwide.

However, it is insufficient only to improve forecasts and their presentation: obstacles to the practical use of the information also need to be addressed, not least of which are funding mechanisms to finance new forecastbased operating procedures (Braman et al. 2012). In Uganda and Togo, a BMZ-funded climate change adaptation project is making use of this concept to pilot changes to traditional humanitarian decision-making. A "preparedness fund" has been established that will be disbursed after a forecast is issued but before a disaster occurs, to fund disaster preparedness actions. Based on flooding frequency and forecast skill, these actions are likely to reduce disaster losses in the long run, even though they will periodically be done "in vain".

Further investment in climate services for disaster risk reduction needs to address such barriers to the use of climate information from the user perspective, not only investing in collaborations to improve scientific information or its presentation, but also investing in the decisionmaking context. Action can be taken to reduce disaster risk based on characterization of changes to climate risk over time, but project cycles and funding opportunities do not always provide an opportunity to implement these actions. Some of the inertia towards using probabilistic forecast information can be addressed directly through flexible funding mechanisms for forecast-based action, which explicitly account for the necessity of "acting in vain" and consequently select appropriate actions for the context. Standard operating protocols that assign pre-determined actions to responsible parties can also institutionalize and systematize action based on climate warnings. The examples of saved lives and livelihoods that can already be attributed to climate services in the humanitarian sector is testament to the potential for increased effectiveness that can be expected with the growth and increasing uptake of this information. 


\section{Competing interests}

The authors declare that they have no competing interests.

\section{Authors' contributions}

SM defined the defined the outline and principles discussed, and helped draft the manuscript; EC reviewed the literature and drafted the manuscript. Both authors read and approved the final manuscript.

\section{Acknowledgements}

Responsible editor: Mimi Sheller

\section{Author details}

${ }^{1}$ Red Cross/Red Crescent Climate Centre, PO Box 28120, 2502 The Hague, KC, Netherlands. ${ }^{2}$ International Research Institute for Climate and Society, The Earth Institute of Columbia University, PO Box 1000, Palisades, NY 10965, USA.

Received: 1 October 2013 Accepted: 17 February 2014

Published: 17 June 2014

\section{References}

Braman L, Suarez P, van Aalst MK (2010) Climate change adaptation: integrating climate science into humanitarian work. Int Rev Red Cross 92:693-712

Braman L, van Aalst MK, Mason SJ, Suarez P, Ait-Chellouche Y, Tall A (2012) Climate forecasts in disaster management: Red Cross flood operations in West Africa, 2008. Disasters 37:144-164

Dilling L, Lemos MK (2010) Creating usable science: opportunities and constraints for climate knowledge use and their implications for science policy. Global Env Change 21:680-689

Hansen JW, Mason SJ, Sun LQ, Tall A (2011) Review of seasonal climate forecasting for agriculture in sub-Saharan Africa. Exp Agric 47:205-240

Hellmuth ME, Mason SJ, Vaughan C, van Aalst MK, Choularton R (2011) A Better Climate for Disaster Risk Management. International Research Institute for Climate and Society (IRI), New York

Hewitt C, Mason SJ, Walland D (2012) The global framework for climate services. Nat Clim Change 2:831-832

Intergovernmental Panel on Climate Change (2012) Managing the Risks of Extreme Events and Disasters to Advance Climate Change Adaptation. A Special Report of Working Groups I and II of the Intergovernmental Panel on Climate Change. Cambridge University Press, Cambridge

Johnston PA, Archer ERM, Vogel CH, Bezuidenhout CN, Tennant WJ, Kuscke R (2004) Review of seasonal forecasting in South Africa: producer to end-user. Clim Res 28:67-82

Kenya Red Cross. Drought (Early Warning Early Action) (2011) Drought Appeal [https://www.kenyaredcross.org/PDF/humanitarian\%20appeals/FRC\%20Drought \%20Appeal\%20Update\%20July\%202011.pdf]

Klopper E, Vogel CH, Landman WA (2006) Seasonal climate forecasts - potential agricultural-risk management tools? Clim Change 76:73-90

McNaught R, Tuimanu V, Braman L (2013) Preparing for ENSO events in the pacific. Climate Serv Partner Case Study. http://www.climate-services.org/ sites/default/files/Pacific_La_Nina_Case_Study.pdf

Meinke H, Howden SM, Struik PC (2009) Adaptation science for agriculture and natural resource management - urgency and theoretical basis. Current Options in Env Sust 1:69-76

Moron V, Robertson AW, Ward MN (2007) Spatial coherence of tropical rainfall at regional scale. J Clim 20:5244-5263

Moron V, Camberlin P, Robertson AW (2013) Extracting subseasonal scenarios: an alternative method to analyze seasonal predictability of regional-scale tropical rainfall. J Clim 26:2580-2600

Ogallo LJ, Bessemoulin P, Ceron JP, Mason SJ, Connor SJ (2008) Adapting to climate variability and change: the Climate Outlook Forum process. J World Meteor Org 57:93-102

Pascal M, Viso AC, Medina S, Delmas MC, Beaudeau P (2012) How can a climate change perspective be integrated into public health surveillance? Public Health 126:660-667

Robertson AW, Moron V, Swarinoto Y (2009) Seasonal predictability of daily rainfall statistics over Indramayu district, Indonesia. Int J Climatol 29:1449-1462

Suarez P, Tall A (2010) Towards forecast-based humanitarian decisions: Climate science to get from early warning to early action. Humanitarian Futures Programme, Kings College, London
United Nations International Strategy for Disaster Reduction (2009) 2009 Global Assessment on Disaster Risk Reduction. Risk and Poverty in A Changing Climate. United Nations International Strategy for Disaster Reduction, Geneva

Usman M, Archer ERM, Johnston P, Tadross MA (2006) A conceptual framework for improving rainfall forecasting for agriculture in semi-arid and dry sub-humid environments. Nat Hazards 34:111-129

Verbist K, Robertson AW, Cornelis WM, Gabriels D (2010) Seasonal predictability of daily rainfall characteristics in central-northern Chile for dry-land management. J Appl Meteorol Climatol 49:1938-1955

Vogel C, O'Brien K (2006) Who can eat information? Examining the effectiveness of seasonal climate forecasts and regional climate-risk management strategies. Clim Res 33:111-112

Webster PJ (2013) Improve weather forecasts for the developing world. Nature 493:17-19

\section{doi:10.1186/2194-6434-1-11}

Cite this article as: Coughlan de Perez and Mason: Climate information for humanitarian agencies: some basic principles. Earth Perspectives 2014 1:11.

\section{Submit your manuscript to a SpringerOpen ${ }^{\circ}$ journal and benefit from:}

- Convenient online submission

- Rigorous peer review

- Immediate publication on acceptance

- Open access: articles freely available online

- High visibility within the field

- Retaining the copyright to your article

Submit your next manuscript at $>$ springeropen.com 